\title{
Consistency in Native Varieties: A Perception of British and American English usage in Cameroon
}

\author{
Nelson Metuk Esou, Ayonghe Lum Suzanne \\ Research Student, University of Bamenda \\ Associate Professor, University of Buea
}

\begin{abstract}
*Corresponding Authors: Ayonghe Lum Suzanne, Associate Professor, University of Buea
Abstract: variety in English language teaching and educators have incessantly insisted on consistency in that variety. With the coming of globalization and instantaneous communication through advanced technology, the educator's insistence on consistency in one native variety of English has of late become questionable. With the use of questionnaires and a reading test, this study set out to examine consistency in BrE taking a sample population of one hundred and twenty-four respondents, representative of Cameroonian speakers of English. Data from the two tests reveal that the respondents obtained a general performance mean score of $54.17 \%$, indicative that Cameroonian speakers of English are inconsistent in the recommended BrE variety due to teachers' lack of knowledge of the native variety they teach, lack of mastery of the differences between the two native varieties, interference from AmE, learners' lack of knowledge of the variety they are learning, lack of simultaneous teaching of BrE and AmE, learning English informally through various media sources, among others. The implications of the study necessitate the introduction of Cameroon Hybrid English (CamHE) which advocates an intra-borrowing between BrE and AmE features in Cameroon.
\end{abstract}

Keywords: British English, American English, varieties, hybrid, mixing, inconsistency

\section{INTRODUCTION}

In recent times Cameroon has witnessed an upsurge in the use of other varieties of the English language. Among the varieties of English used in Cameroon are British English (henceforth BrE) and American English (henceforth AmE). Atechi (2004:20) confirms that "...these two varieties, often referred to as the two main native varieties, are seen by many as the model for other varieties." With the co-existence of BrE and AmE in Cameroon, many users of English often get confused on which of these models they should use when they speak and/or write. In this state of dilemma, many users of English often find themselves caught in a linguistic web leading to an inconsistent use of $\mathrm{BrE}$ and AmE within the same context of usage.

\section{BACKGROUND TO THE STUDY}

English, one of the official languages of Cameroon, has evolved in a number of ways before attaining this status. Kouega (1991) holds that five major linguistic periods, the slave trade period, the free trade period, the German period, the French and English period, and the post re-unification period, contributed in the evolution of English in the country. The English and French period has the greatest linguistic impact on Cameroon as it brought about English and French as the official languages of the country. The post re-unification period cements the linguistic situation of Cameroon as far as English and French are concerned. With the re-unification of West and East Cameroon in 1961, English and French were used in their respective territories until 1972, when a unitary state was declared and thereby adopting English and French as the official languages of the country. Crystal (2003:52) holds that "...the two areas merged as a single country in 1972, with both French and English remaining as official languages." During the English and French Period, the British variety of English was introduced in Cameroon and has been in use till date.

\section{Statement of the Problem}

The homogeneity of English has of late been threatened with the multiplicity of varieties of the language and the advent of hi-tech in a world of globalization. However, British English (BrE) and 
American English (AmE) are the two main native varieties in competition in the world. The Constitution of Cameroon recognizes English as one of the official languages of the country and Crystal (2003:5) opines that "Many countries formally acknowledge a language's status in their constitution (e.g. India); some make no special mention of it (e.g. Britain)." The Constitution stipulates that "The official languages of the Republic of Cameroon shall be English and French, both languages having the same status. The State shall guarantee the promotion of bilingualism throughout the country. It shall endeavour to protect and promote national languages". Despite both the legislators and language policy makers fail to precise on the native variety to use, $\mathrm{BrE}$ is however the de facto variety recommended for teaching in Cameroon. The fact that no official document specifies the variety of English that is used in Cameroon falls in line with Tollefson's (2011:357) view that language policy guidelines or rules "may be explicitly specified in official documents (e.g. a constitution) or implicitly understood, without a written statement." While Belibi (2013:173) asserts that "Standard British English ... still remains the most used and recommended variety for assessment and proficiency testing," Simo Bobda (2002:128) opines that "Most Cameroonians are more exposed to British English than to American English."

Despite BrE serving as the de facto variety for ELT (English language teaching) and most Cameroonians being more exposed to that variety than to the American variety, it has been observed lately with regret and to the disdain of educators and language purists that English language usage in Cameroon is replete with features of AmE in the areas of pronunciation, vocabulary, grammar, spelling, etc. Unlike the British variety that has been implanted in Cameroon through the formal teaching and learning process, the American variety is gaining ground through informal acquisition via modern information and communication techniques. Most Cameroonians watch American movies, for example, and tend to like AmE and consequently want to copy it. Holmes (2013:197) holds that "When the people we mix with regularly belong to a homogeneous group, we tend to speak the way the rest of the group does, provided we want to belong to the group and like the people in it." A direct consequence of the co-existence of $\mathrm{BrE}$ and $\mathrm{AmE}$ in Cameroon is interference as AmE interferes into the speech and/or writing of Cameroonians. The product of this interference is a hybrid variety of English herein referred to as Cameroon Hybrid English (henceforth CamHE). CamHE is manifested when Cameroonian users of English mix BrE and AmE in the same context of usage, plus a local variety of mainstream CamE, be it Cameroon Francophone English (CamFE) or Cameroon Standard English. BrE and AmE are the parents of CamHE, represented symbolically as BrE $+\mathrm{AmE}$ + CamE = CamHE. Language teachers and language purists have incessantly decried the phenomenon of users of English mixing BrE and AmE within the same context of usage and have always reiterated the necessity to be consistent in one variety. Simo Bobda (2002:138) cautions users of English on the necessity to be consistent in one variety, as he puts it, "Most Cameroonians are inclined more towards $\mathrm{BrE}$ than towards AmE. It is therefore advisable to remain consistent within BrE spelling. " At this age of advanced technology and communication when people learn English informally through the Internet, cable television, etc, the call for consistency in one native variety of the language has become questionable not only in Cameroon but in the world at large.

In an attempt for Cameroonian users of English to be consistent in BrE, there is a significant degree of interference from AmE. That is why Barber et al (2009:246) hold that "The development of so many varieties of English has produced problems and controversies about the language, especially in former British colonies ...." In fact, the call for consistency is both a national and international phenomenon as Pikhart (p.102) also points out how Cambridge ESOL stresses candidates' need to be consistent in usage: "Candidates are expected to use a particular variety with some degree of consistency in areas such as spelling, and not, for example, switch from using a British spelling of a word to an American spelling of the same word in the same written response to a given task."

Given the educator's insistence on consistency in BrE at the advent of globalization, the objectives of this paper are therefore to 1) find out if Cameroonians are consistent in the use of the recommended BrE; 2) find out if Cameroonians are taught the differences between the two varieties; 3 ) find out the reasons for mixing $\mathrm{BrE}$ and $\mathrm{AmE}$ and, 4) demonstrate that consistency in one native variety can no longer be attained in Cameroon (in particular and the world at large) due to advancement in technology in a world of globalisation. 


\section{Materials AND Methods}

\subsection{Methods}

The simple random method of the probability sampling technique was initially envisaged to collect data for this study during the 2019/2020 school year though the convenience sampling of the nonprobability technique was also applied due to the coming of the COVID-19 pandemic. Consequently, access to the population was either limited or restricted, making it difficult to randomly sample a large population. Where possible, all the readily accessible respondents of the target schools/institutions were sampled, viz; twenty-one francophone secondary school learners of English, thirty anglophone secondary school learners of English, eleven third-year English students of the University of Yaounde I, sixteen fourth-year bilingual student-teachers of ENS Yaounde, seventeen primary school teachers marking the First School Leaving Certificate (FSLC) 2020 session, twelve secondary and high school teachers of English/Anglais, and seventeen pedagogic inspectors in charge of the teaching of English and the promotion of bilingualism. The one hundred and twenty-four respondents in this study were thus considered representative of Cameroonian users of English, from the learner to the pedagogue.

\subsection{Materials}

The tools used to collect data for this study included questionnaires, a reading passage/test, and observation. The respondents filled in the questionnaire personally without seeking information from someone else as such an attempt could falsify the results of the findings. Depending on the target group, the questionnaires comprised three or four parts. The first part requested personal information; the second part, the level of education and or career. The third part centred on awareness of language varieties. The fourth part cut across all the target groups as respondents demonstrated their knowledge of the similarities/differences between BrE and AmE. A tick was placed in the box that corresponded to the answer and there were open-ended questions for respondents to express their views. It took respondents an average of fifteen minutes to fill-in the questionnaire. All the respondents filled-in the questionnaire though the reading test was done only by those who accepted to read the passage. The reading test was a short passage of an average of thirty seconds' reading at an average pace, totaling seventy-three words. It contained a target of thirteen words whose pronunciation differs in $\mathrm{BrE}$ and $\mathrm{AmE}$. It complemented the questionnaire and was aimed at determining whether Cameroonians are consistent in approximating words following the recommended British pronunciation or whether they mix BrE and AmE pronunciations in their speech.

The respondents familiarized themselves with the passage before reading it and this falls in line with Ur's (1996:50) view that “... the reading passage may include words the interviewee does not know; and perception of spelling affects pronunciation." Each respondent's recorded datum was listened to several times for analysis and interpretation for results. This study was ignited by the observation that $\mathrm{BrE}$ and $\mathrm{AmE}$ were used indiscriminately by learners of English, by teachers and pedagogic inspectors during English Language seminars, in English Language course books, in radio and television broadcasts, in newspapers, just to name but these.

\section{Data Processing}

In the first three parts of the questionnaire all the ticks of the various respondents in a given question were calculated. For example, "Which native variety of English is recommended for teaching in Cameroon?" contained boxes whose answers corresponded to the alternatives, British English (BrE), American English (AmE), and No idea, as the case was. The percentage was derived by adding up all the ticks per given question and dividing the sum by the number of respondents in the target group, and then multiplying the answer by a hundred. The fourth part of the questionnaire cut across all the target groups and it tested respondents' knowledge and ability to recognise and differentiate between $\mathrm{BrE}$ and $\mathrm{AmE}$. Each question consisted of a pair of variant/alternative use of $\mathrm{BrE}$ and $\mathrm{AmE}$ as in the pair, I will visit you Sunday and I will visit you on Sunday. The percentage was obtained by dividing the total number of responses (ticks) by the total number of respondents under study and then multiplying it by a hundred. There were twenty pairs of $\mathrm{BrE}$ and $\mathrm{AmE}$ alternative sentences, amounting to forty questions altogether. In the reading test, the frequency of approximation of a word or sequence of letters either in $\mathrm{BrE}$ or $\mathrm{AmE}$ was calculated and given in percentage. 


\section{Presentation of Findings}

Pedagogic inspectors performed best in the consistency task and the approximation test with a general consistency mean score of 58.89\%. In the consistency task, they obtained a consistency mean score of $67.03 \%$ while in the reading test, they obtained an approximation score of $72.30 \%$ towards BrE and $29.23 \%$ towards AmE; giving an approximation mean score of 50.76\%. When the consistency mean score of $67.03 \%$ and the approximation mean score of $50.76 \%$ are summed up, a general consistency mean score of $58.89 \%$ is derived.

Table showing General Performance for the Consistency Task and the Reading Test

\begin{tabular}{|l|l|l|l|l|}
\hline \multicolumn{1}{|c}{$\begin{array}{c}\text { Group of } \\
\text { Respondents }\end{array}$} & \multicolumn{1}{|c|}{ Consistency Task } & \multicolumn{1}{|c|}{ Reading Test } & \multicolumn{2}{c|}{$\begin{array}{c}\text { General Performance for the } \\
\text { Consistency Task and the } \\
\text { Reading Test }\end{array}$} \\
\cline { 2 - 6 } & $\begin{array}{c}\text { Consistency Mean } \\
\text { Score }\end{array}$ & $\begin{array}{c}\text { Approximation } \\
\text { Mean } \\
\text { Score }\end{array}$ & $\begin{array}{c}\text { General Consistency } \\
\text { Mean } \\
\text { Score }\end{array}$ & Ranking \\
\hline $\begin{array}{l}\text { Pedagogic } \\
\text { inspectors }\end{array}$ & 67.03 & 50.76 & 58.89 & $1^{\text {st }}$ \\
\hline $\begin{array}{l}\text { Secondary } \\
\text { teachers }\end{array}$ & 66.05 & 49.99 & 58.02 & $2^{\text {nd }}$ \\
\hline University students & 64.48 & 49.99 & 57.24 & $3^{\text {rd }}$ \\
\hline Student-teachers & 62.95 & 49.99 & 56.47 & $4^{\text {th }}$ \\
\hline $\begin{array}{l}\text { Anglophone } \\
\text { learners }\end{array}$ & 59.02 & 49.72 & 54.37 & $5^{\text {th }}$ \\
\hline $\begin{array}{l}\text { Francophone } \\
\text { learners }\end{array}$ & 51.95 & 46.92 & 49.43 & $6^{\text {th }}$ \\
\hline $\begin{array}{l}\text { Primary s. teachers } \\
\text { Mean Score }\end{array}$ & $\begin{array}{l}51.40 \\
\mathbf{5 9 . 3 5}\end{array}$ & 46.15 & 48.77 & $7^{\text {th }}$ \\
\hline General Performance Mean Score & & $\mathbf{4 9 . 0 0}$ & $\mathbf{5 4 . 1 7}$ & \\
\hline
\end{tabular}

The pedagogic inspectors' high approximation score towards BrE depicts them as models in the domain who ought to be emulated. Despite the pedagogic inspectors obtained the highest general consistency mean score, they were nonetheless inconsistent in the attribution of native varieties to their corresponding sentences; also, they were inconsistent in the approximation of words towards their respective native varieties. They were neither consistent in assigning all the twenty pairs of sentences to the same corresponding native variety nor did they unanimously approximate all the thirteen words towards BrE. Secondary and high school teachers came second with a general consistency mean score of $58.02 \%$. In the consistency task, they obtained a consistency score of $69.44 \%$ in BrE and $62.67 \%$ in AmE, giving a consistency mean score of $66.05 \%$. The teachers moreover obtained an approximation score of $66.15 \%$ towards BrE and $33.84 \%$ towards AmE, giving an approximation mean score of $49.99 \%$. The varying figures reveal that the secondary and high school teachers were inconsistent in attributing native varieties to their respective sentences in the same way as they were inconsistent in approximating the thirteen target words towards one native variety. Third-year students of the Department of English came third in the rankings as they obtained a general consistency mean score of $57.24 \%$. In the consistency test, the students obtained a consistency score of $68.75 \%$ in $\mathrm{BrE}$ and $60.22 \%$ in AmE, giving a consistency mean score of $64.48 \%$. They also had an approximation score of $63.07 \%$ towards BrE and $36.92 \%$ towards AmE, yielding an approximation mean score of 49.99 .

The disparity in the scores reveals that they were not consistent in their approximation of words towards one native variety and were equally inconsistent in attributing words towards the corresponding native variety. Student-teachers were fourth with a general consistency mean score of $56.47 \%$. They too, like their counterparts, were not consistent and unanimous in the attribution of words in the corresponding native variety; neither did they approximate all the thirteen target words towards one native variety of English. The student-teachers obtained a consistency score of $64.84 \%$ in $\mathrm{BrE}$ and $61.07 \%$ in AmE, giving a consistency mean score of $62.95 \%$. They moreover had an approximation score of $66.15 \%$ towards BrE and $33.84 \%$ towards AmE, giving an approximation mean score of $49.99 \%$. Anglophone learners were fifth with a general consistency mean score of 
$54.12 \%$. In the consistency task, they obtained a consistency score of $60.06 \%$ in BrE and $57.97 \%$ in AmE, giving a consistency mean score of $59.02 \%$. In the reading test, they obtained an approximation score of $64.61 \%$ towards BrE and $33.84 \%$ towards AmE, giving an approximation mean score of 49.72. The learners, like their teachers and inspectors, were not consistent in attributing native varieties to their respective sentences, neither did they approximate all the thirteen target words towards one native variety.

Francophone learners were sixth and they obtained a general consistency mean score of $49.43 \%$. In the consistency task, they obtained a mean consistency score of $53.33 \%$ in $\mathrm{BrE}$ and $50.57 \%$ in $\mathrm{AmE}$, yielding a consistency mean score of $51.95 \%$. They equally obtained an approximation score of $58.46 \%$ towards $\mathrm{BrE}$ and $35.38 \%$ towards $\mathrm{AmE}$, giving an approximation mean score of $46.92 \%$. Primary school teachers came last with a general consistency mean score of $48.77 \%$. In the consistency test, they obtained a consistency score of $61.39 \%$ in BrE and $41.41 \%$ in AmE, summing up 51.40\% consistency mean score. They obtained an approximation score of $60 \%$ towards $\mathrm{BrE}$ and $32.30 \%$ towards AmE, giving an approximation mean score of 46.15 . They, like all the rest of the respondents, were not consistent in attributing all the sentences to their respective native varieties, neither did they approximate all the thirteen words towards BrE.

\section{DISCUSSION}

Given that our aim in this study was to use the sample population to refute or confirm and generalize the tendency observed, and taking into consideration the data obtained so far, data reveal that Cameroonian users of English use $\mathrm{BrE}$ and $\mathrm{AmE}$ inconsistently both in writing and in speech; though statistics show that they are more consistent in writing than in speech. There are reasons so far for the inconsistency observed in the use of native varieties. Though a majority of teachers are aware that $\mathrm{BrE}$ is the recommended native variety for teaching and learning, others have no idea of the native variety of English they teach their learners, consequently, teachers teach features of both $\mathrm{BrE}$ and AmE and their learners in turn mix these varieties. Also, Teachers do not master the differences that exist between the two native varieties, consequently, both features of $\mathrm{BrE}$ and $\mathrm{AmE}$ are taught at all the levels of education, from primary school, through secondary and/high school to university level. Interference from AmE and Teachers' false allegiance for the recommended $\mathrm{BrE}$ is another cause for inconsistency. Many teachers portray a false allegiance for the recommended BrE when indeed they teach a mixed variety of $\mathrm{BrE}$ and $\mathrm{AmE}$ features, which their learners in turn learn, and the chain continues.

This false allegiance for BrE ties in with Atechi (2008:193) who holds that "Although there is no text that specifies the model to be used in the Cameroonian classroom, most teachers and learners think that since formal education started in Cameroon with the BrE model, ... it should normally be the model to look to." Data moreover reveal that teachers hardly inform their learners of the native variety of English they are learning. Consequently, they teach both features of $\mathrm{BrE}$ and $\mathrm{AmE}$ and the learners on the receiving end cannot not distinguish between the native varieties. Had the teachers informed their learners of the native variety they are learning, the teachers would do everything possible to stick to that variety. Moreover, there is lack of simultaneous teaching of $\mathrm{BrE}$ and AmE. Even though teachers are aware that $\mathrm{BrE}$ and $\mathrm{AmE}$ co-exist (in the education sector in Cameroon), the two native varieties are not taught simultaneously to the learners in a bid for them to be aware of the differences between the varieties and be consistent in the recommended BrE variety, if consistency is really required. Also, learners are introduced to both varieties only when they get to their third year of university studies and solely in the Department of English. Unfortunately, the bulk of Cameroonian users of English who do not read English at university are bound to mix varieties. Moreover, the teaching of variety studies is not profound to cover all the areas of the differences between BrE and AmE and as such, users mix varieties due to lack of profound knowledge of all the existing and numerous differences between the varieties. Various media sources like the Internet, the radio, the television, etc., are also greatly responsible for the inconsistency with which Cameroonians use $\mathrm{BrE}$ and $\mathrm{AmE}$. Users of English get in contact with one variety of English, for example, BrE, through one medium and yet get in contact with another variety, say, AmE, through another medium. At times, users of English get in contact with both BrE and AmE through the same medium, for example, the American Cable News Network $(\mathrm{CNN})$ where some presenters are BrE speakers while others are AmE speakers. 
The inconsistency in English language (BrE and $\mathrm{AmE}$ ) is also responsible for the mixing of varieties of English. AmE spellings have $i u$ as in condominium but in other cases there is the absence of the $i$, as in aluminum while in BrE both condominium and alluminium are spelt with $i u$. This inconsistency in English spelling may be misleading to a Cameroonian user of English who uses both spellings of aluminum and alluminium. Inconsistency in English does not only exist between the two native varieties but also within a native variety itself. Another cause of inconsistency in English is the use of American English in computer spell-check software program. No matter how consistent one may want to be in $\mathrm{BrE}$, some computer in-built spell-check are AmE-programmed. Also, many people prefer using AmE words for convenience sake as they are shorter and easier to spell than their $\mathrm{BrE}$ equivalents. Words like program, cab, encyclopedia, , etc., are not only shorter but also easier to spell than their BrE equivalents; programme, taxi, encyclopaedia. Most Cameroonians use AmE words by way of analogy. Francophone users of English assume that words like centre, programme, etc. are French-spelt words; consequently, their corresponding equivalents in English are center, program, etc. Because of this analogous usage, inconsistency abounds in the text of some francophone users of English.

\section{TEACHING IMPLICATIONS OF THE STUDY}

The Kachruvian model of Three Concentric Circles has given licence to non-native societies to use and adapt the English language to their idiosyncratic needs, given that the language is no longer the sole possession of native speakers but is now a joint property of all those who use it. The adaptation of English to the needs of non-native speakers has as priority an intranational function which Schneider (2011:345) acknowledges in the following words: "In ESL countries, typically former parts of the British Empire, English fulfills important intranational functions as an official or semi-official language..." Unlike purists assume that the New Englishes are intended to be used on the international scene, Kachru (1991) holds that such communication is rather for internal purpose. Atechi (2008:195) maintains that "Cameroonians need English more for intranational communication than for international communication." It is first and foremost this intranational function of English that strongly necessitates an entirely new paradigm in English language teaching in Cameroon. In fact, there are reasons that necessitate the simultaneous teaching of British and American English in the Cameroonian classroom.

First of all, the pressure AmE exerts on BrE is manifested in the way the British borrow AmE words and expressions and this necessitates the teaching of AmE in Cameroon. Peters and Fee (1989) quoted in Modiano (1996:207) hold that "There is substantial evidence that people in Britain are borrowing American lexical items, as well as adopting AmE spelling conventions." It is important to point out here that the British themselves, whose variety of English serves as our model of reference, borrow features of American English. If the British, the native speakers of our reference variety, borrow features of American English, what then is expected of Cameroonians, non-native speakers of English? Can Cameroonians be more consistent in BrE than the British themselves? The absurdity with which educators, nationally and internationally, require learner-consistency in one native variety has been pointed out by Case (2019) who states: "When Canadians, Australians and the millions of people with "mid-Atlantic" English use forms from both British and American English and borrowing between the two forms is becoming more and more common, it seems silly to ask even high level learners to choose one or the other." It is against this backdrop of the recommendation of BrE as the exclusive reference variety vis-à-vis the British occasional use of AmE features that this study advocates the teaching of Cameroon Hybrid English (CamHE). The use of BrE and AmE varieties as the reference educational standards is gaining international reputation. Modiano (1996:207) holds that "Many educational establishments in Europe have already adopted a teaching philosophy based on the multiplicity of English and have gone beyond exclusively promoting BrE. Several countries now officially accept both American and British English." The two varieties are so intertwined that Modiano (1996:208) believes "...it is no longer possible to hold the two varieties of the English language separate."

The inexhaustive differences between $\mathrm{BrE}$ and $\mathrm{AmE}$ calls for the harmonization and interchangeable use of the two varieties. Though differences between BrE and AmE are said to be "few", these differences are however inexhaustible to non-native speakers of English. That is why Simo Bobda (2002:128) says: "I am going to introduce you to some of these differences, classified by level of 
analysis, and by register" probably because he is not exhaustive or detailed in his presentation. Furthermore, Modiano stated in Arnold (1998:97) warns that "No effort has been made to include all of the significant differences between AmE and BrE" in his A Mid-Atlantic Handbook of American and British English. On a similar note, Simo Bobda and Mbangwana (1993:192) say, "We have chosen to introduce you to non-RP accents of English: General American (GenAm) and Cameroon English (CamE)." Only (third-year) university students of the Department of English have up to date had the opportunity to be "introduced" to AmE meanwhile consistency in BrE is a requirement for every Cameroonian user of English. This gives them a slight edge in consistency over students of other disciplines who have not learned the differences between the two varieties.

The simultaneous teaching of $\mathrm{BrE}$ and $\mathrm{AmE}$ will therefore give learners the exposure to both varieties and attempt consistency in a given variety where necessary. Another reason that necessitates the teaching of $\mathrm{BrE}$ and $\mathrm{AmE}$ in Cameroon is the lack of consistency in BrE observed at all levels of education in the country where futile attempts are made to diverge the two varieties through the recommendation of the exclusive use of $\mathrm{BrE}$. This can be seen where the University of Bamenda, for example, recommends British English as the native variety to be used in students' dissertations and theses. The University of Bamenda Thesis and Dissertation Guide (2018:31) stipulates: "Dissertations and Theses in The University of Bamenda must be written in English. ... The use of British English is compulsory." The Guide is however self-contradictory as its vocabulary fluctuates between BrE and AmE spellings. Examples of such inconsistent usage are, Enrolment [BrE]/ Fulfillment [AmE]; Defence $[\mathrm{BrE}] /$ Defense $[\mathrm{AmE}]$; Authorisation $[\mathrm{BrE}] /$ Authorize $[\mathrm{AmE}]$, etc. This is proof that the phenomenon of inconsistency equally reigns in higher education in Cameroon.

In secondary education, the instructions of the G.C.E O/L and A/L English Language Paper, 2020 session, are marred with inconsistency as there is Mobile phones [BrE]; zero [AmE]; and Fill in [BrE]. The Anglais paper of the Probatoire exam for the 2020 session bears dialogue [BrE]; practice (v) $[\mathrm{AmE}]$; cell phone $[\mathrm{AmE}]$; practised $[\mathrm{BrE}]$, etc. Given the inability for Cameroonians at all levels of education to be consistent in the recommended $\mathrm{BrE}$ due to the worldwide influence of $\mathrm{AmE}$, this study advocates the teaching of CamHE which involves the simultaneous teaching and interchangeable use of both BrE and AmE features within the context of Cameroon. Cave (2019), no doubt, advises students and users of English as a whole, that both British and American models are correct, so they should not "... waste time 'correcting' themselves when they have actually used one of the acceptable forms," and adds that "...almost no one needs to remember which form is British and which is American." Modiano (1996:209) adds that "strict adherence to BrE denies many students an opportunity to learn the English which they find most desirable." Ur (1996:56) is of the opinion that the distinction between BrE and AmE is no longer necessary nowadays, as she puts it, “... even this distinction is becoming less important as time goes on ... it is a good idea to give learners at least some exposure to others, through the use of "live" speakers or recordings, in order to raise awareness of other possible accents...."

While we advocate the simultaneous teaching of $\mathrm{BrE}$ and $\mathrm{AmE}$ in Cameroon, we moreover advocate the teaching of the local form of CamE on the other hand. Atechi (2004:199) is also positive about the teaching of CamE as "...the variety takes into account the sociolinguistic and cultural realities of the Cameroon local linguistic landscape.” Ngefac (2011:43) suggests that “...only uneducated CamE features should be discouraged. The educated aspects of CamE can be conveniently promoted on the Cameroonian landscape...." CamE teachable features should include aspects of our local culture like food (njamajama, eru), clothes (kaba, ndop cloth), music (bottle dance, assiko), etc. aimed at promoting the Cameroonian culture as a whole. Angwah (2019:12) opines that with an exposure to CamE, learners will master the Cameroonian culture which will eventually gain international recognition.

\section{CONCLUSION}

This study has shown that Cameroonian users of English, from the learner to the pedagogue, are inconsistent in the recommended BrE. The study has further demonstrated that consistency in one native variety can no longer be attained due to the intertwined nature of the two varieties as well as the advancement in technology in a world of globalization. The study advocates the simultaneous teaching of $\mathrm{BrE}$ and $\mathrm{AmE}$ in the Cameroonian classroom, as well as the teaching of educated CamE features which nonetheless are importance to the language learner. 


\section{ACKNOWLEDGEMENT}

Nelson Metuk Esou conceived of the project, carried out the survey and drafted the manuscript, S. Ayonghe guided the research process and edited the manuscript.

\section{REFERENCES}

Atechi, Samuel Ngwa. (2008). The Dilemma of the Teacher and the Learner of English in the non-native English Classroom: The case of Cameroon. In Alizés : Revue Angliciste de La Réunion, Faculté des Lettres et Sciences humaines (Université de La Réunion) Dilemnas,pp.181-198.Retrieved from http://labor atoires.univ-reunion.fr/oracle/documents/the_dilemma.html (May 2020).

Case, Alex. (2019). "How to Teach British and American English." Retrieved from www.usingenglish.com, accessed 23 June, 2021.

Kachru, Braj B. (1991) "World Englishes and Applied Linguistics". Retrieved from www.eric.ed.gov. November 2019.

Pikhart, Jan. Varieties of English and Exams: Standard English? Retrieved from scholar.google.com, 27 April, 2020.

\section{BIBLIOGRAPHY}

Angwah, Julius M. (2019) “Cameroonian ESL Teachers' Linguistic Perceptions and Some Phonological Aspects of Their English" Journal of Literature, Languages and Linguistics, Vol.57, 2019. P.7-12.

Arnold, Martin (1998). "Marko Modiano, A Mid-Atlantic Handbook: American and British English." In American Studies in Scandinavia. Vol. 30, pp 97-99.

Atechi, Samuel Ngwa. (2004). "The Intelligibility of Native and Non-native English Speech: A Comparative Analysis of Cameroon English and American and British English." PhD Thesis. University of Chemnitz, Germany.

Barber, Charles; Joan C. Beal \& Philip A. Shaw. (2009). The English Language: A Historical Introduction (2nd Edn). Cambridge: Cambridge University Press.

Belibi, Patrick R. (2013). "Teaching a Standard Variety of English or a Local Standard: The Case of Cameroon" in International Journal of English Language Education Vol. 1, No. 3, pp.172-185.

Constitution of the Republic of Cameroon, Part I, Article 1(3). Law No. 96-06 of 18 January 1996 to amend the Constitution of 2 June 1972.

Crystal, David. (2003). English as a Global Language. (2nd Edn). Cambridge: Cambridge University Press.

Holmes, Janet. (2013). An Introduction to Sociolinguistics (4th edition). New York: Routledge.

Kouega, Jean Paul. (1991). "Some speech characteristics of Cameroon Media News in English: An Eploratory Study of Radio and Television News Texts." Doctorat de Trosième Cycle Thesis. University of YaoundeI.

Modiano, Marko. (1996). "The Americanization of Euro-English” in World Englishes, Vol. 15, No 2, pp. 207215.

Ngefack, Aloysius. (2011). "When the Blind Lead the Blind: The Fallacy of Promoting Standard British English Accent in Cameroon", in Journal of Language Teaching and Research. Vol 2, No 1, pp. 40-44.

Schneider, Edgar W. (2011) "Colonization, Globalization, and the Sociolinguistics of World Englishes" in The Cambridge Handbook of Sociolinguistics. Mesthrie, Rajend (Ed). Pp 335-353.

Simo Bobda, Augustin \& Paul Mbangwana. (1993). An Introduction to Spoken English. Lagos: University of Lagos Press.

Simo Bobda, Augustin. (2002). Watch Your English: A Collection of Remedial Lessons on English Usage. Yaounde: B\&K Language Institute.

Tollefson, James W. (2011) "Language Planning and Language Policy" in The Cambridge Handbook of Sociolinguistics. Mesthrie, Rajend (ed). Pp 357-376.

University of Bamenda. (2018). Thesis and Dissertation Guide. Bamenda: UBa. Ur, Penny. (1996). A Course in Language Teaching. Cambridge: Cambridge University Press.

Citation: Nelson Metuk Esou \& Ayonghe Lum Suzanne. "Consistency in Native Varieties: A Perception of British and American English usage in Cameroon" International Journal on Studies in English Language and Literature (IJSELL), vol 9, no. 9, 2021, pp. 48-55. doi: https://doi.org/10.20431/2347-3134.0909005.

Copyright: (1) 2021 Authors. This is an open-access article distributed under the terms of the Creative Commons Attribution License, which permits unrestricted use, distribution, and reproduction in any medium, provided the original author and source are credited. 